\title{
An experimental study of the $\mathrm{CO}_{2}$ hydrates production for the long term storage
}

\author{
Ondřej Bartoš ${ }^{1 *}$, and Matěj Hrnčír ${ }^{1}$ \\ ${ }^{1}$ CTU in Prague, dep. Energy Engineering, Technická 4, Prague 6, 166 07, Czechia
}

\begin{abstract}
An aim of the paper is to show recent data obtained from a new experimental set-up build for the production of the $\mathrm{CO}_{2}$ gas hydrates. The purpose of the experimental set-up is to analyse the practical aspects of the transformation gaseous $\mathrm{CO}_{2}$ to the hydrates. The deserving effort to decrease impacts of the global warming is containing the more questionable attempt to capture the $\mathrm{CO}_{2}$ produced within the electricity production and to avoid a releasing to the atmosphere. The storage in the form of the gas hydrates present an alternative way to more known technologies involved in the projects of CCS (Carbon Capture and Storage). The production of the gas hydrate is observed in the set-up with simultaneously acquired data of state condition close to the phase boundary. The presented work has two goals, first is the estimation of the transformation efficiency of the $\mathrm{CO}_{2}$ to the hydrates in compare with the theory and second goal is obtaining of the data for new $\mathrm{CO}_{2}$ hydrates production set-up with liquid circulation and possibility to separate pure hydrate. The experimental analysis of the gas hydrates production process can help to estimate the practical aspects of the hydrates production for a possibility of $\mathrm{CO}_{2}$ storage in this form.
\end{abstract}

\section{Introduction}

As concerns about greenhouse gases such as $\mathrm{CO}_{2}$ are still not sufficiently solved, it has been proposed to isolate its hydrates form at great ocean depths [1]. Regarding the standard condition, one can expect that $1 \mathrm{~m} 3$ of hydrate contains approximately $170 \mathrm{~nm} 3$ of CO 2 with depending on the formation process. Investigating the properties of $\mathrm{CO}_{2}$ hydrate and reaction kinetics both in the laboratory and in the marine environment is important for a potential industrial way to long lasting storage of the $\mathrm{CO} 2$ without danger of the sudden release of the gas to the atmosphere. Therefore, a reliable, reproducible and effective method for the synthesis of $\mathrm{CO}_{2}$ hydrate should be found. The purpose of this work should be performed the observation and measurement of the state condition of the hydrates formation in laboratory conditions, both in fresh water and in saline [2]. The thermodynamics steady state condition of the $\mathrm{CO} 2$ hydrates formation is at significantly higher pressure than atmosphere. From this reason a measurement set-up to study hydrates formation was developed and manufactured. The hydrates are formed on the phase boundary and this results that not all supplying gas is transformed to the hydrate. This paper present the data from the measurement of the formation process with the effort to establish the efficiency of the gas transformation. The

* Corresponding author: ondrej.bartos@,fs.cvut.cz 
measurement set-up was equipped with the precise measurement of the temperature and gas flow. Obtained experience will be used for the development of the more advance facility which will be close to the real industry.

Hydrates are the crystalline products (clathrate) of water interactions with inorganic and organic substances, and are characterized by a strict structure for the given type of substance. All hydrophobic gases and volatile organic compounds have the ability to form hydrates since their molecular size will be $3.8-9.2 \AA\{10-10 \mathrm{~m}\}$ (Ar, N2, O2, CH4, C2H4, C2H6, C3H8, iso-C4H10, $\mathrm{Cl} 2, \mathrm{CS} 2)$ and hydrophilic compounds ( $\mathrm{CO} 2, \mathrm{SO} 2)$, ethylene oxide $(\mathrm{C} 2 \mathrm{H} 4 \mathrm{O})$, tetrahydrofuran (THF, C4H8O), acetone. By their shape, the hydrates resemble snow or loose ice, but under normal atmospheric conditions, hydrates are rarely encountered [3].

The hydrates storage on the deep ocean bottom requires a detailed study of the deep ocean condition and properties of the hydrates namely the density. The density of the hydrates is very close to the density of the sea water on the bottom. The density of the hydrate is higher than the density of the sea water but the hydrate produced in the laboratory contains small bubbles and its density is lower than the water. This is one of many reason for study of the production process in the laboratory.

\section{Measurement setup}

The aim of the experiment was to create carbon dioxide hydrate $(\mathrm{CO} 26 \mathrm{H} 2 \mathrm{O})$ in laboratory conditions and confirm that $\mathrm{CO} 2$ can be produced for the further storage. The carbon dioxide is drawn to the nozzle under the water level and released as the bubbles through the cold distilled, drinking or salty water.

The set-up (Fig. 1) contains pressure vessel (reactor) made from cast iron and is equipped with two $15 \mathrm{~mm}$ thick borosilicate glass in both front and rear to observe the formation of hydrates. Stainless steel flanges tightened with four M12 screws are located at the top and bottom. In the lower flange there is a pressure gauge and a hole for cooling water hoses. In the top flange there is a blow-off valve, carbon dioxide inlet port and a thermometerpositioning tube that measures the inner temperature of the vessel. On the sides of the pressure vessel there are welded tubes with holes for the hoses through which there is a device inside which the gas can be released from the bottom through the individual bubbles. Under this device, there is a copper pipe coil, which is also supplied with cooling water, to cool the vessel more efficiently. In our case, an operational temperature is above $1^{\circ} \mathrm{C}$ to avoid the water freezing. The interior of the pressure vessel was coated with the zinc paint which was proved as the best protection against the corrosion. Cooling system is connected to the thermal bath to maintain constant temperature.

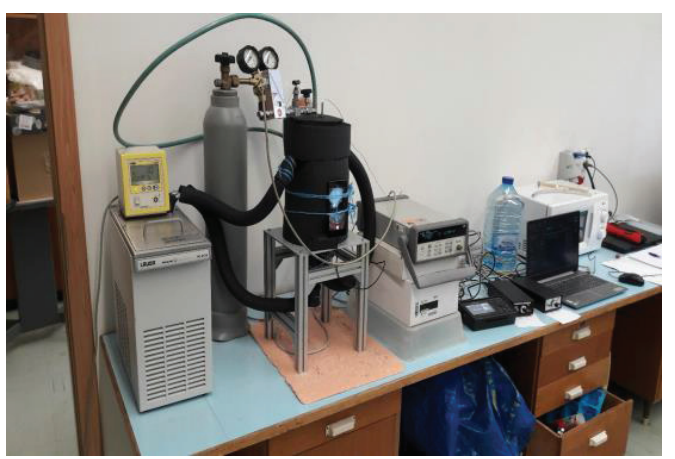

(a)

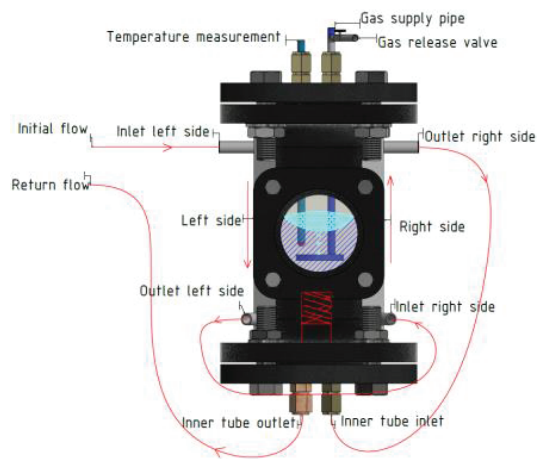

(b)

Fig. 1. Entire set-up (a), Schema of the reactor connection (b). 
The instrumentation of the experiment consists of the classical probes. RTD precisely calibrated for the measurement of the reactor internal temperature and the inlet and outlet of the cooling water together with the its flow by the vortex flowmeter. Pressure is the measured by standard transducer and mass flow of the $\mathrm{CO} 2$ is measured by the mass flow meter. Data are acquired by the datalogger. Entire reactor and connecting pipes are isolated by the PP foam.

\section{Acquired data}

The production of the $\mathrm{CO} 2$ hydrate in the set-up was initialized when the temperature in the reactor interior decreased under the equilibrium temperature corresponding with the pressure [4]. See Fig 2a. The hydrate nucleation starts very slowly at the beginning and sub-cooling of few degrees Celsius is necessary. On the Fig. $2 b$ are presented the capture images of the hydrates. The measurement set-up was design only for a demonstration of the hydrates formation, but after gaining some experimental skills the precise measurement of the energy fluxes was performed. The aim was to compare the heat released while the hydrates are produced with the $\mathrm{CO} 2$ mass flow to the reactor. The result would be efficiency of the transformation. The direct determination of the formed hydrate is not possible due to the high pressure in the reactor, only non-direct determination methods are available.

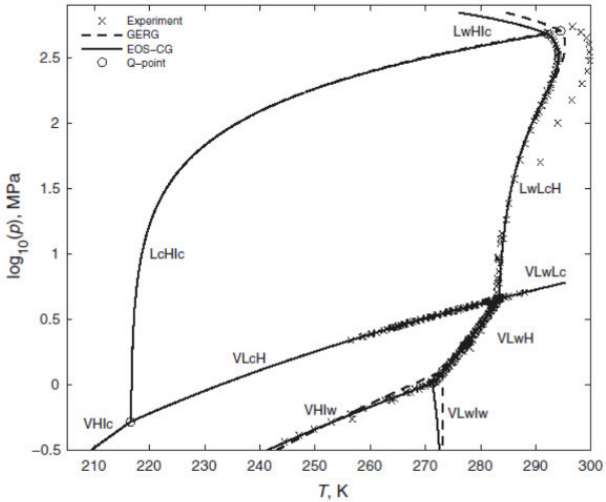

(a)

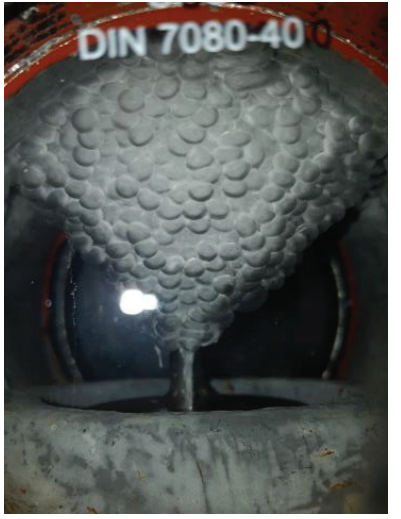

(b)

Fig. 2. $\mathrm{CO}_{2}$-Water-Hydrate phase diagram [4] (a), Hydrate in the reactor in a typical "bubble" structure (b).

The measurement of the temperature inside of the reactor and temperature of the cooling water at the inlet and outlet is shown on the Fig. 3. The mass flow of the cooling water was nearly constant app. $1.68 \mathrm{~L} / \mathrm{min}$. The start of the production was app. at 14:34 and the end 14:44 when the pressure inside the reactor was decreased. Several measurement were performed but in the paper only one measurement is shown. 


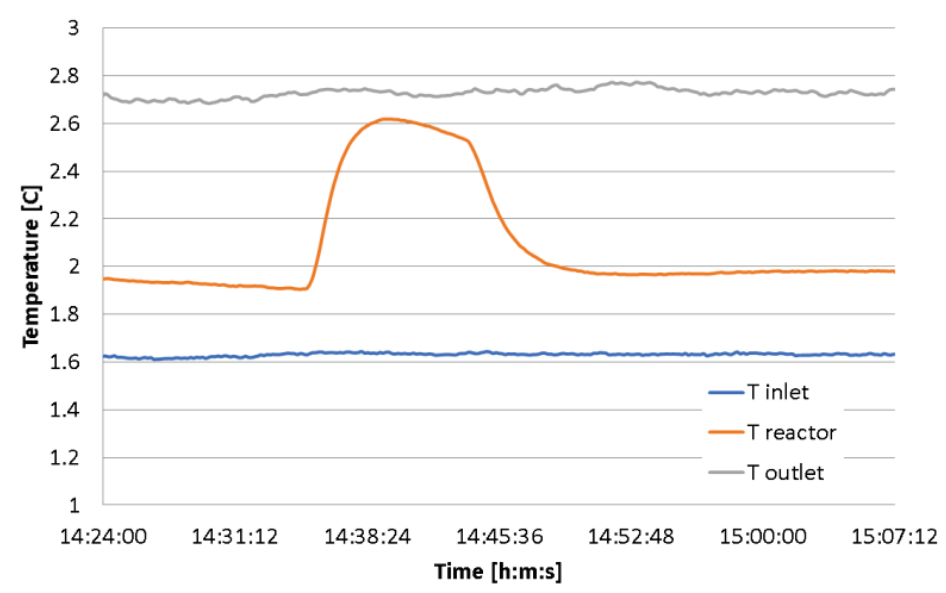

Fig. 3. The temperature inside the rector when the hydrate was produced

\section{Data processing and results}

The main goal for the data processing was to determine the amount of the hydrate in the reactor. The direct measurement is impossible due to the high pressure inside the vessel. From this reason some non-direct method were tested. The first way how to determine the mass of the hydrate formed in the reactor is from the heat balance. The hydrate formation energy is known app. $\mathrm{Hf}=65 \mathrm{~kJ} / \mathrm{mol}$. Several measurements were averaged and the average formation rate $0.05 \mathrm{~mol} / \mathrm{min}$. The second way is to measure direst flow of the gas to the reactor at the inlet and outlet. The difference should be the hydrate formation rate. Unfortunately this method is not possible to use in this simple manner. Two mass-flow meters were used on the inlet and the outlet of the reactor, but both gauges work at the different pressure with different gas than the gas for the calibration. The entire measurement chain contains many uncertainties which cause the high inaccuracy of the measurement. Even the solubility of the $\mathrm{CO} 2$ and accumulation in the reactor were involved.

Another method for the determination of the transformation ate is modelling the process in the Simulink environment. For the simulation the simple equation of the energy conservation was used (1).

$$
m_{w} c_{p} \frac{d T}{d t}=H_{f} \frac{d m_{g}}{d t}-C_{2}\left(T-T_{i n}\right)
$$

where $\mathrm{T}$ temperature in the reactor, $\mathrm{m}_{\mathrm{w}}$ is mass of the water in the reactor, $\mathrm{c}_{\mathrm{p}}$ specific heat capacity, $\mathrm{H}_{\mathrm{f}}$ hydrate formation enthalpy, $\mathrm{T}_{\text {in }}$ temperature of the cooling water, $\mathrm{m}_{\mathrm{g}}$ mass of the transformed $\mathrm{CO}_{2}, \mathrm{C}_{2}$ unknown constant which respect heat transfer from the reactor. 


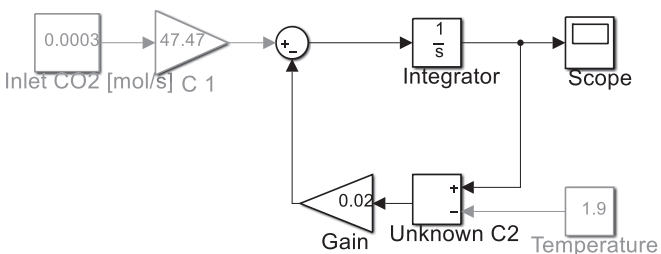

(a)

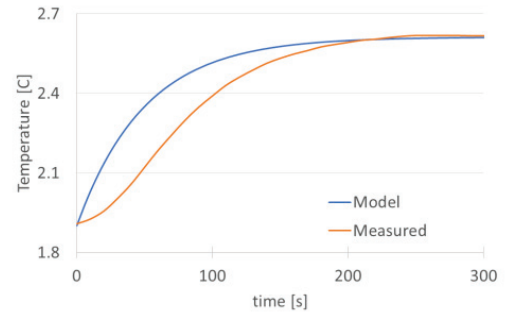

(b)

Fig. 4. The temperature inside the rector when the hydrate was produced

On the Fig. $4 \mathrm{a}$ and $\mathrm{b}$ are shown the wire diagram and progress of the measured and the modelled temperature profile. The eq. 1 describes 1 st order system, but measured profile seems to be rather more 2 nd order system, but after the more advance simulation we found that this is sufficient description, because main reason for the second order system is the delay in the temperature measurement. The RTD probe is in the pipe which protect the probe against the high pressure. The final transformation rate was determined $0.02 \mathrm{~mol} / \mathrm{min}$.

\section{Conclusion}

The current experiment proves that suggested method is possible to use for the $\mathrm{CO} 2$ hydrates production, but bigger set-up for production testing would be better. The direst measurement of the transformation efficiency or measurement of the formed hydrate amount is hardly achievable, but the combination of the energy flux measurement and numerical simulation one can get a promising result.

The obtained knowledge presented in this paper will be used for the construction of the bigger unit for the hydrate production with focusing on the industrial use. Main goal will be determined the energy required for the hydrates production. This will be crucial information if the storage in form of hydrates should be studied more.

The more general effect of this work is gaining knowledges around the gas hydrates, for example methane hydrates are presented on the sea bottom and in the permafrost in the north areas of the Earth and in the future the releasing of the methane to the atmosphere due to the global warming and make a greenhouse effect even worse.

We gratefully acknowledge the support by the Grant Agency of the Czech Technical University in Prague, Grant No. SGS 21/154.

\section{References}

1. "Gas hydrates for deep ocean storage CO2", Aker Kvaerner, (2003)

2. O. Bartoš, S. Chystiakov and P. Hýbek, "A study of $\mathrm{CO}_{2}$ hydrates for deep ocean storage", ERIN, The 13th International Conference for Young Researchers and $\mathrm{PhD}$ Students April 9th-11th, (2019), Blansko - Češkovice, Czech Republic

3. E.D. Sloan, C.A. Koh, "Clathrate Hydrates of Natural Gases", third ed., CRC Press, Taylor \& Francis group, New York, (2008)

4. A. Jägera, V. Vinš a J. Gernert, "Phase equilibria with hydrate formation in $\mathrm{H} 2 \mathrm{O}+$ CO2 mixtures modeled with“" Fluid Phase Equilibria, (2013) 